\title{
The p53-Bcl-2 connection
}

\author{
MT Hemann ${ }^{1}$ and SW Lowe ${ }^{*}, 1$
}

${ }^{1}$ Cold Spring Harbor Laboratory, Howard Hughes Medical Institute, Cold Spring Harbor, NY, USA

The tumor suppressor p53 and the proto-oncogene Bcl-2 were two of the earliest identified cancer genes. Mutant p53 proteins were first discovered in transformed murine cell lines, ${ }^{1,2}$ whereas Bcl-2 translocations were first identified in human follicular lymphoma. ${ }^{3,4,5}$ Despite this shared cancer relevance, they were initially thought to have little else in common. p53 was proposed to activate cell cycle check-points, ${ }^{6}$ whereas Bcl-2 was shown to inhibit cell death. Additionally, Bcl-2 overexpression was found exclusively in hematopoietic cancers, whereas p53 mutations were primarily found in solid tumors. However, the last 15 years have witnessed the emergence of strong genetic and biochemical ties between these two proteins, and it has become increasingly evident that signaling between p53 and Bcl-2 is of fundamental importance to cancer biology. This News and Commentary will focus on the pathways connecting p53 with Bcl-2 and the deregulation of this signaling network during tumor development.

p53 is a sequence-specific transcription factor that is activated by diverse forms of cellular stress. ${ }^{7}$ Early studies of p53 focused on the ability of tumor-derived p53 mutants to promote cell growth and transformation. ${ }^{8-10}$ Subsequently, p53 was characterized as an essential mediator of cell cycle arrest in response to diverse cellular stresses. ${ }^{11,12}$ The first suggestion that p53 could promote apoptosis came more than 10 years after its discovery from experiments in which p53 was introduced into a p53-deficient leukemia cell line. These experiments showed that enforced p53 expression could induce cell death in cells deprived of prosurvival cytokines. ${ }^{13}$ Subsequently, work in p53 knockout mice demonstrated that p53 activity was essential for radiation-induced death in thymocytes and chemotherapy-induced apoptosis in fibroblasts expressing deregulated oncogenes. ${ }^{14-16}$

Importantly, the ability of p53 to promote cell death could be directly linked to its tumor suppressive function. Development of certain tumors in p53 null mice was associated with decreased cell death rather than increased cell cycle progression. ${ }^{17,18}$ Additionally, certain tumor-derived p53 mutants were shown to be impaired for apoptosis induction, but capable of promoting cell cycle arrest. ${ }^{19,20}$ Early studies also indicated that the proapoptotic activity of p53 correlated with its ability to function as a transcription factor, as tumor-derived p53 mutants defective in their ability to bind DNA in a sequence-specific manner were also found to be impaired for apoptosis induction. ${ }^{21,22}$ Still, some studies suggested p53 may promote apoptosis through transcription-independent functions. ${ }^{23,24}$ Only in the last decade have the relevant $\mathrm{p} 53$ targets in apoptosis come into focus. It now appears that the primary

*Corresponding author: S Lowe, Cold Spring Harbor Laboratory, Howard Hughes Medical Institute, 1 Bungtown Road, Cold Spring Harbor, NY 11724, USA. Tel: 516367 8406; Fax: 516367 8454; lowe@ cshl.edu. 
action of p53 in apoptosis is to directly and indirectly regulate the activity of the Bcl-2 family proteins.

\section{p53 Transactivation of Proapoptotic Bcl-2 Family Members}

The first mechanistic connection between p53 and Bcl-2 came from the identification of the proapoptotic 'multi-domain' Bcl-2 family member Bax, initially identified by the Korsmeyer laboratory. ${ }^{25}$ p53 directly induces Bax transcription. ${ }^{26}$ Additionally, Bax induction by stress-activated p53 can overcome the antiapoptotic effects of Bcl-2, and cells deficient for Bax are resistant to certain stimuli known to promote p53-dependent apoptosis. ${ }^{27,28}$ For example, deregulated oncogene expression induces p53-dependent apoptosis that is attenuated in the absence of Bax. ${ }^{27}$ Thus, p53-mediated regulation of the ratio of Bax versus $\mathrm{Bcl}-2$ protein level can influence the fate of a cell in response to stress.

However, p53-mediated transactivation of Bax does not fully explain the ability of p53 to inhibit Bcl-2 and promote apoptosis. For example, Bax-deficient thymocytes and intestinal epithelial cells readily undergo apoptosis in response to gamma-irradiation ${ }^{29,30}$ - situations in which p53-deficient cells do not. Additionally, Bax-deficient fibroblasts are significantly more sensitive than p53-deficient fibroblasts to chemotherapy-induced cell death. ${ }^{27}$ Finally, Bax-deficient mice are not overtly tumor prone. ${ }^{29}$

This discrepancy between the phenotype of p53 and Bax null cells and mice can be explained, in part, by the action of $\mathrm{p} 53$ on the proapoptotic 'BH3-only' class of Bcl-2 family members. These proteins act upstream of Bax and induce the activation of multi-domain proapoptotic proteins. ${ }^{31}$ Several of these proteins, including Puma, Noxa and possibly Bid, are direct transcriptional targets of $\mathrm{p} 53 .{ }^{32-35}$ Studies involving cells deficient for individual BH3-only proteins have identified apoptotic roles for these proteins that potentiate Baxdependent apoptotic pathways. For example, Puma-deficient colorectal cancer cells are resistant to hypoxia-related apoptosis and Puma suppression prevents Myc-induced apoptosis in B cells ${ }^{33,36}$ - situations in which p53 is known to mediate cell death. In both these contexts, Puma requires Bax to kill cells. Conversely, some p53-induced BH3-only proteins provide parallel signals that may simply reinforce the proapoptotic potential of Bax. For example, Noxa, like Bax, promotes p53-dependent apoptosis in fibroblasts in response to DNA damage. ${ }^{37}$ Finally, certain p53-upregulated BH3-only proteins are essential for Bax-independent cell death. Notably, Puma-deficient thymocytes are resistant to apoptosis induced by gamma-radiation. ${ }^{38,39}$ Thus, $\mathrm{p} 53$ engages many proapoptotic transcriptional targets, the relevance of which may vary significantly in different cellular contexts or in response to distinct cellular stresses.

\section{Transactivation-Independent p53 Regulation of Bcl-2}

In addition to its ability to promote the transcription of Bcl-2 antagonists, p53 employs additional strategies to regulate Bcl-2. For example, p53 can act to repress Bcl-2 transcription in some settings. Hence, introduction of p53 into certain p53 null cell lines results in repressed Bcl-2 gene expression, ${ }^{40,41}$ and induction of p53 using gammairradiation leads to reduced $\mathrm{Bcl}-2$ expression in leukemia cells. ${ }^{42}$ Although the mechanism for such repression is not completely clear, the Bcl-2 promotor contains a p53-negative 
response element, ${ }^{43}$ raising the possibility that Bcl-2 may be a direct target of p53-mediated transrepression.

p53 may also directly impact Bcl-2 activity as part of a transcription-independent program of cell death. In this process, cytoplasmic p53 binds to proapoptotic Bcl-2-family proteins, leading to permeabilization of mitochondria and apoptosis. ${ }^{44-46}$ Consequently, p53, itself, may act like a BH3-only protein and antagonize Bcl-2 function. Interestingly, structural studies have shown that the DNA-binding domain of p53 is required for direct p53-Bcl-2 interaction. ${ }^{47,48}$ Thus, tumor-derived p53 mutants impaired for DNA binding may also be impaired for Bcl-2 interaction. Although the relative contribution of the transcriptiondependent and independent effector functions of p53 remains a topic of debate, these processes may also cooperate to promote cell death. For example, p53-induced PUMA protein is capable of disrupting cytosolic p53-Bcl-2 complexes, thereby releasing p53 to directly induce apoptosis at the mitochondria. ${ }^{49}$ Thus, p53 can regulate Bcl-2 levels and activity through diverse mechanisms, all of which may be required to efficiently engage the cell death machinery.

\section{Overcoming the Apoptotic Threshold}

The identification of a myriad of proapoptotic p53 targets that each bind and inhibit antiapoptotic Bcl-2 family members suggests that it is only through the combined transcriptional activation of numerous proapoptotic targets that p53 exerts its full apoptotic capability. Similarly, a combination of p53-dependent and independent signals establishes a total apoptotic burden in a cell that stands in opposition to the prosurvival function of Bcl-2. Included in this apoptotic load are a number of BH3-only proteins that show no obvious regulation by $\mathrm{p} 53$, yet antagonize $\mathrm{Bcl}-2$ function in response to specific cellular stresses. For example, the BH3-only proteins Bim, Bad and Hrk are induced by cytokine deprivation in a p53-independent manner, ${ }^{50}$ yet these proteins may synergize with $\mathrm{p} 53$-induced pathways to overcome the antiapoptotic threshold set by Bcl-2 and promote cell death.

In 'sensitized' cell types, the total apoptotic burden in a cell is precariously balanced against the strength of the antiapoptotic Bcl-2 family members (Figure 1). For example, cells expressing deregulated oncogenes activate $\mathrm{p} 53$-dependent and independent apoptotic pathways that render these cells highly vulnerable to additional apoptotic stimuli. ${ }^{51,52}$ Exposing these cells to known inducers of p53, like DNA damage-inducing chemotherapy, or stresses that activate parallel apoptotic pathways, like cytokine deprivation, readily tips these cells over the Bcl-2 threshold to induce apoptosis. Conversely, the inactivation of any single apoptotic pathway in oncogene-expressing cells may accommodate a level of oncogenic activity sufficient to promote transformation and tumorigenesis.

One biologically relevant setting in which the impact of apoptotic thresholds becomes apparent is in murine models of Myc-induced B-cell lymphoma. Deregulated Myc expression promotes $\mathrm{p} 53$-dependent apoptosis, ${ }^{53,54}$ but it also promotes the $\mathrm{p} 53$-independent activation of the proapoptotic $\mathrm{BH} 3$-only protein Bim. ${ }^{55}$ Targeted inactivation of either the p53 or Bim pathway in Myc-expressing B cells is sufficient to promote tumor development. ${ }^{55,56}$ Similarly, tumor-derived Myc mutants that show impaired Bim 
activation, but normal p53 induction, are highly tumorigenic. ${ }^{57}$ This also appears to be the case in human Burkitt's lymphoma, where both Bim and p53 deregulation exist, but are mutually exclusive. Thus, p53-dependent and independent signals act in parallel to promote cell death and suppress tumorigenesis. The combined strength of these signals is required to overwhelm the antiapoptotic Bcl-2 family members, such that inactivation of any one of several prodeath effectors can drop the system below its apoptotic firing threshold and allow unabated proliferation. Consequently, the proapoptotic effect of p53 signaling can be blunted without mutations in the linear program connecting p53 and Bcl-2.

\section{Relevance of the p53-Bcl-2 Pathway to Cancer}

Although p53 and Bcl-2 both represent focal nodes in convergent apoptotic signaling pathways, p53 loss and Bcl-2 overexpression are not equivalent lesions with respect to their impact on tumor phenotypes. First, p53 and Bcl-2 alterations are found in overlapping, but distinct, sets of human malignancies. ${ }^{58,59}$ Second, whereas p53-deficient mice rapidly develop diverse tumor types, ${ }^{60} \mathrm{Bcl}-2$ transgenic mice exclusively develop hematopoietic malignancies and then only after a long latency. ${ }^{61}$

The broader spectrum of tumor phenotypes produced by $\mathrm{p} 53$ mutations can be attributed to the diverse cellular functions of p53. In addition to promoting apoptosis, p53 is also essential for the induction of cell cycle arrest or cellular senescence in response to diverse cellular stresses. Consequently, disruption of p53's arrest functions may be required to support tumorigenesis in some situations. For example, certain p53 mutants, defective in apoptosis but not cell cycle arrest, are impaired in their ability to initiate T-cell lymphomagenesis. ${ }^{62}$ Additionally, in settings where there is a high apoptotic threshold, p53 may trigger other effector processes, such as cell cycle arrest. This is apparent in MEFs lacking an oncogene, which are intrinsically resistant to apoptosis, and in Myc-induced lymphomas expressing high levels of Bcl-2. ${ }^{63,64}$ Here, activation of p53 leads to cell cycle arrest or cellular senescence, respectively.

In contrast, p53 loss and Bcl-2 overexpression can have virtually identical effects on tumor pathology in some situations. In these contexts, p53's tumor suppression may be mediated primarily by its ability to transactivate proapoptotic targets and induce cell death. An example of this comes from studies involving the p53 target gene Puma. Puma is a critical proapoptotic target of p53 but is not required for mediating p53-dependent cell cycle arrest. ${ }^{32,33}$ Mice deficient for Puma are not overtly tumor prone, ${ }^{38}$ supporting a critical role for evasion of cell cycle arrest or other p53-effector functions during tumor development in p53 null mice - where p53 loss acts as an initiator of tumorigenesis. However, in the presence of deregulated Myc expression, Puma deficiency promotes B cell lymphomagenesis as efficiently as p53 loss. ${ }^{36}$ Thus, in specific contexts, p53 tumor suppression is mediated exclusively by signaling through the $\mathrm{p} 53-\mathrm{Bcl}-2$ pathway. In these cases, cell cycle defects and genomic instability may simply represent by-products of p53 loss that are irrelevant for the initial steps of cell transformation.

Still, these by-products may provide new capabilities that become relevant later during tumor progression or in response to cancer therapy, producing tumors that are more 
aggressive than those acquiring strictly antiapoptotic lesions. Consequently, the high frequency and broad distribution of $\mathrm{p} 53$ versus $\mathrm{Bcl}-2$ alterations in cancer may more accurately reflect the relevance of these proteins to tumor evolution as opposed to early tumor development.

Given the high frequency of Myc deregulation in human cancers, it seems likely that the targeted inactivation of mediators of p53-dependent apoptosis may supplant the requirement for p53 loss in a variety of tumorigenic settings. However, the status of most proapoptotic Bcl-2 family members in human malignancies remains unclear. Of note, Bax alterations have been found in both hematopoietic and gastrointestinal tumors. ${ }^{65-67}$ In addition, Bim loss has been documented in $17 \%$ of human MALT lymphomas. ${ }^{68}$ Whether Puma, Noxa or other $\mathrm{BH} 3$-only proteins are similarly inactivated in human malignancy remains to be determined. Importantly, owing to the sensitivity of the apoptotic threshold to subtle changes in prodeath signals, genes encoding proapoptotic Bcl-2 family members can be haploinsufficient for tumor suppression. For example, loss of a single Bim allele or incomplete RNAi-mediated suppression of Puma is sufficient to promote Myc-induced lymphomagenesis. ${ }^{55,69}$ Thus, studies that exclusively score the presence or absence of these genes in human tumors may significantly underestimate their relevance to cancer development.

\section{Conclusions}

The convergence of $\mathrm{p} 53$ on various aspects of Bcl-2 biology highlights the crucial role of this interaction in tumor suppression and drug response. Thus, promoting the p53-Bcl-2 interaction seemingly provides an ideal strategy for anticancer therapies. However, significant challenges remain in determining when and how best to re-engage this apoptotic network. First, whereas cancer cells commonly exhibit apoptotic defects, it will be important to identify tumorigenic contexts in which apoptotic lesions are central to tumor maintenance. Second, because the relevance of specific p53-induced effector proteins and antiapoptotic Bcl-2 family members may vary in distinct tumorigenic contexts, understanding the precise apoptotic pathways abrogated in specific malignancies will be essential for devising targeted proapoptotic therapies. This includes expanding our understanding of how parallel apoptotic pathways synergize with p53-Bcl-2 signaling to promote cell death. Finally, although the development of novel inhibitors of antiapoptotic Bcl-2 family members holds great promise, significant effort will be required to understand the genetic basis for susceptibility or resistance to these drugs and to devise combination therapies that potentiate their action.

\section{References}

1. Linzer DI, Levine AJ. Cell. 1979; 17:43-52. [PubMed: 222475]

2. Lane DP, Crawford LV. Nature. 1979; 278:261-263. [PubMed: 218111]

3. Tsujimoto Y, et al. Science. 1985; 229:1390-1393. [PubMed: 3929382]

4. Bakhshi A, et al. Cell. 1985; 41:899-906. [PubMed: 3924412]

5. Cleary ML, Sklar J. Proc Natl Acad Sci USA. 1985; 82:7439-7443. [PubMed: 2865728]

6. Korsmeyer SJ. Blood. 1992; 80:879-886. [PubMed: 1498330]

7. Ko LJ, Prives C. Genes Dev. 1996; 10:1054-1072. [PubMed: 8654922]

8. Eliyahu D, et al. Nature. 1984; 312:646-649. [PubMed: 6095116] 
9. Parada LF, et al. Nature. 1984; 312:649-651. [PubMed: 6390217] 10. Jenkins JR, et al. Nature. 1984; 312:651-654. [PubMed: 6095117]

11. Kastan MB, et al. Cancer Res. 1991; 51:6304-6311. [PubMed: 1933891]

12. Kastan MB, et al. Cell. 1992; 71:587-597. [PubMed: 1423616]

13. Yonish-Rouach E, et al. Nature. 1991; 352:345-347. [PubMed: 1852210]

14. Clarke AR, et al. Nature. 1993; 362:849-852. [PubMed: 8479523]

15. Lowe SW, et al. Cell. 1993; 74:957-967. [PubMed: 8402885]

16. Lowe SW, et al. Nature. 1993; 362:847-849. [PubMed: 8479522]

17. Schmitt CA, et al. Cancer Cell. 2002; 1:289-298. [PubMed: 12086865]

18. Symonds H, et al. Cell. 1994; 78:703-711. [PubMed: 8069917]

19. Ryan KM, Vousden KH. Mol Cell Biol. 1998; 18:3692-3698. [PubMed: 9632751]

20. Ludwig RL, et al. Mol Cell Biol. 1996; 16:4952-4960. [PubMed: 8756654]

21. Attardi LD, et al. EMBO J. 1996; 15:3693-3701. [PubMed: 8758936]

22. Jimenez GS, et al. Nat Genet. 2000; 26:37-43. [PubMed: 10973245]

23. Haupt Y, et al. Genes Dev. 1995; 9:2170-2183. [PubMed: 7657168]

24. Caelles C, et al. Nature. 1994; 370:220-223. [PubMed: 8028670]

25. Oltvai ZN, et al. Cell. 1993; 74:609-619. [PubMed: 8358790]

26. Miyashita T, Reed JC. Cell. 1995; 80:293-299. [PubMed: 7834749]

27. McCurrach ME, et al. Proc Natl Acad Sci USA. 1997; 94:2345-2349. [PubMed: 9122197]

28. Yin C, et al. Nature. 1997; 385:637-640. [PubMed: 9024662]

29. Knudson CM, et al. Science. 1995; 270:96-99. [PubMed: 7569956]

30. Pritchard DM, et al. Oncogene. 1999; 18:7287-7293. [PubMed: 10602483]

31. Opferman JT, Korsmeyer SJ. Nat Immunol. 2003; 4:410-415. [PubMed: 12719730]

32. Nakano K, Vousden KH. Mol Cell. 2001; 7:683-694. [PubMed: 11463392]

33. Yu J, et al. Proc Natl Acad Sci USA. 2003; 100:1931-1936. [PubMed: 12574499]

34. Sax JK, et al. Nat Cell Biol. 2002; 4:842-849. [PubMed: 12402042]

35. Oda E, et al. Science. 2000; 288:1053-1058. [PubMed: 10807576]

36. Hemann MT, et al. Proc Natl Acad Sci USA. 2004; 101:9333-9338. [PubMed: 15192153]

37. Shibue T, et al. Genes Dev. 2003; 17:2233-2238. [PubMed: 12952892]

38. Jeffers JR, et al. Cancer Cell. 2003; 4:321-328. [PubMed: 14585359]

39. Villunger A, et al. Science. 2003; 302:1036-1038. [PubMed: 14500851]

40. Haldar S, et al. Cancer Res. 1994; 54:2095-2097. [PubMed: 8174112]

41. Miyashita T, et al. Oncogene. 1994; 9:1799-1805. [PubMed: 8183579]

42. Zhan Q, et al. Oncogene. 1997; 14:1031-1039. [PubMed: 9070651]

43. Miyashita T, et al. Cancer Res. 1994; 54:3131-3135. [PubMed: 8205530]

44. Moll UM, et al. Curr Opin Cell Biol. 2005; 17:631-636. [PubMed: 16226451]

45. Erster S, Moll UM. Biochem Biophys Res Commun. 2005; 331:843-850. [PubMed: 15865940]

46. Talos F, et al. Cancer Res. 2005; 65:9971-9981. [PubMed: 16267022]

47. Petros AM, et al. FEBS Lett. 2004; 559:171-174. [PubMed: 14960327]

48. Tomita Y, et al. J Biol Chem. 2006; 281:8600-8606. [PubMed: 16443602]

49. Chipuk JE, et al. Science. 2005; 309:1732-1735. [PubMed: 16151013]

50. Willis SN, Adams JM. Curr Opin Cell Biol. 2005; 17:617-625. [PubMed: 16243507]

51. Lowe SW, et al. Nature. 2004; 432:307-315. [PubMed: 15549092]

52. Lowe SW. Endocr Relat Cancer. 1999; 6:45-48. [PubMed: 10732786]

53. Hermeking H, Eick D. Science. 1994; 265:2091-2093. [PubMed: 8091232]

54. Evan GI, et al. Cell. 1992; 69:119-128. [PubMed: 1555236]

55. Egle A, et al. Proc Natl Acad Sci USA. 2004; 101:6164-6169. [PubMed: 15079075]

56. Schmitt CA, et al. Genes Dev. 1999; 13:2670-2677. [PubMed: 10541553]

57. Hemann MT, et al. Nature. 2005; 436:807-811. [PubMed: 16094360] 
58. Zornig M, et al. Biochim Biophys Acta. 2001; 1551:F1-F37. [PubMed: 11591448]

59. Cory S, et al. Oncogene. 2003; 22:8590-8607. [PubMed: 14634621]

60. Donehower LA, et al. Nature. 1992; 356:215-221. [PubMed: 1552940]

61. McDonnell TJ, Korsmeyer SJ. Nature. 1991; 349:254-256. [PubMed: 1987477]

62. Liu G, et al. Nat Genet. 2004; 36:63-68. [PubMed: 14702042]

63. Serrano M, et al. Cell. 1997; 88:593-602. [PubMed: 9054499]

64. Schmitt CA, et al. Cell. 2002; 109:335-346. [PubMed: 12015983]

65. Kondo S, et al. Cancer Res. 2000; 60:4328-4330. [PubMed: 10969770]

66. Meijerink JP, et al. Blood. 1998; 91:2991-2997. [PubMed: 9531611]

67. Rampino N, et al. Science. 1997; 275:967-969. [PubMed: 9020077]

68. Tagawa H, et al. Oncogene. 2005; 24:1348-1358. [PubMed: 15608680]

69. Dickins RA, et al. Nat Genet. 2005; 37:1289-1295. [PubMed: 16200064] 


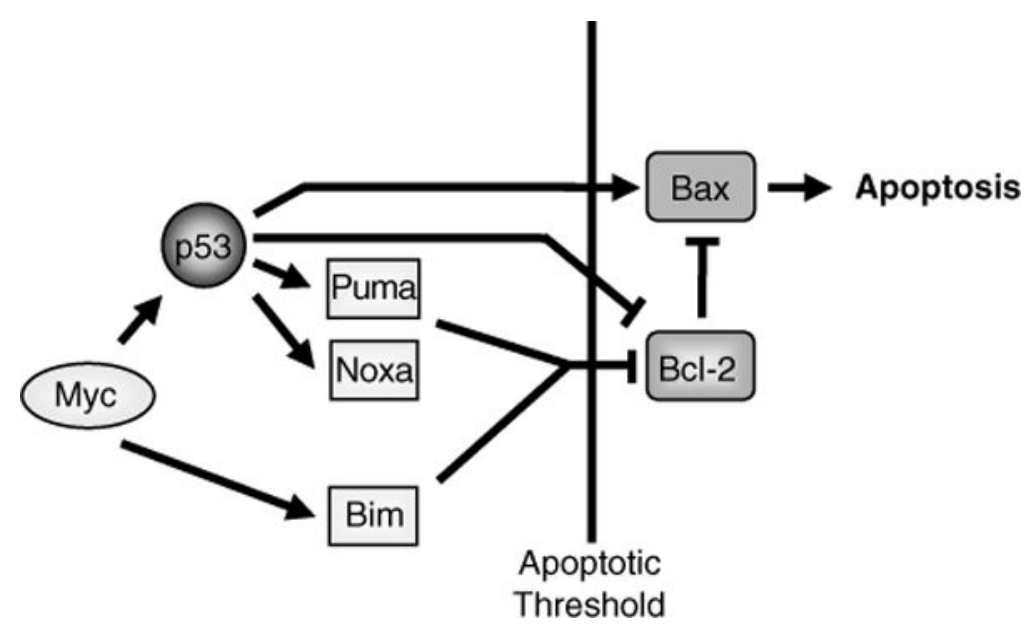

Figure 1.

Overcoming the antiapoptotic threshold set by Bcl-2 family members. p53-dependent signals, including the induction of Bax, Puma and Noxa and direct inhibition of Bcl-2, synergize with p53-independent signals, like the induction of Bim, to antagonize Bcl-2 function and promote apoptosis 